\title{
Efficacy of 6-Month Adapted Aerobic Program on Motor Proficiency, BMI and Cognitive Abilities of Students with Autism Spectrum Disorder: Three Case Reports
}

\author{
Georgia Strofylla, Sofia Charitou, Katerina Asonitou, Dimitra Koutsouki \\ Laboratory of Adapted Physical Activity, Developmental and Physical Disabilities, School of Physical Education and Sport Science, \\ National \& Kapodistrian University of Athens, Athens, Greece \\ Email: gstrofylla@phed.uoa.gr
}

How to cite this paper: Strofylla, G., Charitou, S., Asonitou, K., \& Koutsouki, D. (2021). Efficacy of 6-Month Adapted Aerobic Program on Motor Proficiency, BMI and Cognitive Abilities of Students with Autism Spectrum Disorder: Three Case Reports. Open Journal of Social Sciences, 9, 153-166. https://doi.org/10.4236/jss.2021.99011

Received: August 13, 2021

Accepted: September 4, 2021

Published: September 7, 2021

Copyright $\odot 2021$ by author(s) and Scientific Research Publishing Inc. This work is licensed under the Creative Commons Attribution International License (CC BY 4.0).

http://creativecommons.org/licenses/by/4.0/

\begin{abstract}
Adolescents with Autism Spectrum Disorder (ASD) face particular difficulties that impact their opportunities to participate in regular physical activities. According to the recent literature, exercise seems to have numerous benefits for students with ASD such as improvements in fundamental motor skills, balance and in physical fitness generally. The purpose of the present study was to investigate the efficacy of 6-months adapted aerobic program on motor performance, Body Mass Index (BMI) and cognitive abilities in three adolescent boys with ASD. The study included two phases: baseline and post test. Motor performance of participants with ASD was evaluated with the Movement Assessment Battery for Children-Second Edition and cognitive abilities were assessed with the Cognitive Assessment System. Participants were administered also anthropometric measures (weight, height, waist circumference). Results indicated that participation in the aerobic program can improve participants' motor proficiency, body composition and cognitive abilities. Developing exercise intervention programs to improve motor proficiency, physical fitness and cognitive abilities of children and youth with ASD should be a priority by the community in order to increase their overall health-related physical fitness.
\end{abstract}

\section{Keywords}

Autism Spectrum Disorder, Motor Proficiency, Body Mass Index (BMI), Waist Circumference, Cognitive Abilities, Adapted Aerobic Program 


\section{Introduction}

Autism Spectrum Disorder (ASD) is a complex lifelong neurodevelopmental disorder typically characterized by deficits in socialization and communicative skills as well as restricted and repeated patterns of behavior (APA, 2013). However, recent evidence suggests that children with ASD experience motor coordination delays and deficits that contribute to atypical development of fundamental motor skills (Xavier, Gauthier, Cohen, Zahoui, Chetouani, Villa, Berthoz, \& Anzalone, 2018). Motor deficits in children with ASD are characterized by difficulties in fundamental movement patterns, balance, postural stability, coordination deficits and Developmental Coordination Disorder (Ferreira, Toscano, Rodrigues, Furtado, Barros, Wanderley, \& Moreira Carvalho, 2018).

Children with ASD tend to be overweight or obese than their peers without ASD (Broder-Fingert, Brazauskas, Lindgren, Iannuzzi, \& Van Cleave, 2014). One study reported $43 \%$ of students with ASD were overweight. A highly prevalence of obesity in children and youths with disabilities might lead to serious health consequences such as cardiovascular disease and psychological issues (McMullen, 2014) due to decreased energy expenditure as result in decreased participation in physical activities, inappropriate eating habits and chronic diseases (Hinckson, Dickinson, Water, \& Sands, 2013; Tyler, Schramm, Karafa, Tang, \& Jain, 2011). So it is of major important to increase participation in physical activities among children and adults with ASD. Body Mass Index (BMI) constitutes the most common indicator to classify obesity on children and adults. BMI can be defined as the ratio of the weight (in kilograms) to the square of the height (in meters squared) $\left(\mathrm{kg} / \mathrm{m}^{2}\right)$.

A growing body of researchers takes an interest in investigating the positive effects of adapted physical exercise programs for students with Autism Spectrum Disorder over the last decades (Healy, Nacario, Braithwaite, \& Hopper, 2018). Specifically, the main point of studies focuses on how is going to improve the impairments of the disorder through the participation of students with Autism Spectrum Disorder in exercise interventions (Rosenblatt, Gorantla, Torres, Yarmush, Rao, Park, Denninger, Benson, Fricchione, Bernstein, \& Levine, 2011). On a wide-ranging educational curriculum of the Greek Ministry of Education for students with Autism Spectrum Disorders is referred that, "Students with Autism Spectrum Disorder is a neuro-developmental disorder characterized with a large heterogeneity on their motor skills and motor difficulties regarding the course of physical education" (Greek Ministry of Education and Religious Affairs, Institute of Educational Policy, 2003: p. 307). The effects of adapted physical activity programs have been studied in children and adolescents with ASD (Young \& Furgal, 2016). In one study it was evaluated the effect of 8-weeks structured training program of traditional dance on neuromuscular coordination of ten individuals with and without ASD (Arzoglou, Tsimaras, Kotsikas, Fotiadou, Sidiropoulou, Proios, \& Bassa, 2013) with the Korperkoordinationstest fur Kinder (KTK) (Kiphard \& Schilling, 2007). Researchers found that not only is a systematic and 
well-designed Greek traditional dance training program beneficial for individuals with ASD but also be able to improve their neuromuscular coordination. An interesting 3-months yogic intervention was applied for children and adolescents with ASD. Participants were familiar with yogic practices including OM Chanting, Asanas and Pranayama (Deorari \& Bhardwaj, 2014). Researchers concluded that continuous practice of yoga may significantly improve the autism-specific behavior difficulties in children with ASD. Similar results found Sequeira and Ahmed study (Sequeira \& Ahmed, 2012) about meditation as a potential therapy for children with ASD. Researchers conducted a review about mantra meditation and suggested that might be a useful intervention for children with ASD between 3 and 14 years of age to improve stereotypes, social and communicational deficiencies.

Jogging and water intervention programs are the most common aerobic activities studied in children with ASD. Water activities have been found to improve inappropriate behavior and motor difficulties in children with ASD (Dartt, 2015; Yanardag, Erkan, Yılmaz, Arıcan, \& Düzkantar, 2015). Yilmaz, Yanardag, Birkan and Bumin (2004) found that swimming training had positive affections on child's physical fitness (balance, cardiorespiratory endurance, flexibility, agility and power) as well as stereotypic behaviors such as spinning, swinging and echolalia. Similar results found in Fragala-Pinkham and Haley study (2011). In their pilot study assessed the effect of 14-weeks aquatic exercise program on physical fitness of children with ASD, 6 - 12 years old. It was found that participants on the intervention program exhibited better swimming skills, improved attention on homework, better social skills and nonverbal communication behavior. Another study reported that an aquatic program could improve significantly the aquatic skills of students with ASD, aged 7 - 12 years old, as well as their physical fitness (BMI). The active and regular participation in structured physical activities has significant effects in better quality of life in people with disabilities (Pan, 2011).

\section{Purpose of the Study}

Since one of the core defining characteristics of the disorder is issues in social interaction and communication most of the intervention programs are targeted on this domain and physical activity intervention is often overlooked in students with ASD. However, in recent studies is mentioned that perceptual-motor difficulties might not be one of the core characteristics of the disorder but are present in children with ASD and affect their everyday activities and lifestyle (Gowen \& Hamilton, 2013). From the review of the literature, the majority of studies are focused primarily on social and cognitive deficits and there are no adequate results about the efficacy of an intervention exercise program on population with ASD. According to the recent research results, there is a close interrelationship between motor performance and cognitive abilities in children with atypical development (Alesi, Battaglia, Roccella, Testa, Palma, \& Pepi, 2014). The aim of the present study was to evaluate the effects of an adapted aerobic program on 
motor proficiency, cognitive abilities and weight outcomes of three adolescent boys with Autism Spectrum Disorder. It was hypothesized that:

- The 6-months intervention aerobic program would improve motor proficiency and body composition of students with ASD.

- The 6-months intervention aerobic program would have significant effect on cognitive abilities of students with ASD of students with ASD.

\section{Method}

\subsection{Participants}

Three adolescent boys with Autism Spectrum Disorder and aged between 13 - 15 years old (Mean Age $=14.4$ ) participated in the present study. The inclusion criteria were: 1) to be diagnosed with ASD by the public diagnostic center of Greece at the age of 32 months, 2) to be medically able to participate in aerobic training, 3) participants should not have surgeries during the last twelve months and 4) to have signed informed consent from their caregivers. During the present study, participants attended a special education class in a public primary school in Northern Greece.

At the beginning on the intervention program were accomplished anthropometric measures (weight, height and waist circumference measurements). Participants were weighed and measured in light clothing without shoes using a Seca ${ }^{\mathrm{TM}}$ 803 portable digital flat scale and measured using a $200 \mathrm{~cm}$ wall mounted height meter stadiometer. Finally, a measuring tape was used for the waist circumference measurement. Body Mass Index $\left(\mathrm{BMI}, \mathrm{kg} / \mathrm{m}^{2}\right)$ was calculated for the participants from measures of height and weight. Underweight, normal weight, overweight and obesity were defined according to the gender and age-specific Body Mass Index (BMI) cut-off points by the International Obesity Task Force (IOTF) recommendations, using international references values based on data from six countries (Cole, Bellizzi, Flegal, \& Dietz, 2000).

\subsection{Instruments}

\subsubsection{Movement Assessment Battery for Children-2 (MABC-2)}

Motor performance of student with ASD was evaluated with the Movement Assessment Battery for Children-Second Edition (MABC-2) (Henderson, Sugden, \& Barnett, 2007). MABC-2 is a validated, norm-referenced test and one of the most widely used assessment tools for the screening, identification and description of impairments in children's motor functioning and planning intervention programs. MABC-2 measures both fine and gross motor competence skills in three age bands (3:00 to 6:11 years, 7:00 to 10:11 years, and 11:00 to 16:11 years). In the present study were used motor skills from the third age band (11:00 to $16: 11$ years). It is an individually administered test that takes between $20^{\prime}$ to $40^{\prime}$ minutes to complete. It involves a total of eight tasks in three subscales consisting of manual dexterity, aiming and catching, and balance. Scoring is based on quantitative measures such as the number of successful trials and the length of 
time taken to complete a task. For each subscale, raw scores are converted to agespecific standard scores. Standard scores for each subscale are summed and converted to an age-specific standard and percentile score for total performance on the MABC-2. A "traffic light system" is developed for the classification of motor performance. For example, scores at or below 5th percentile (red zone) indicates significant movement difficulty, 6th-15th percentile (amber zone) falls in the "at risk" of having a movement difficulty; and above 15th percentile (green zone) indicates no movement difficulty detected (Henderson, Sugden, Barnett, Brown, \& Lalor, 2009).

\subsubsection{Cognitive Assessment System (CAS)}

Cognitive abilities of students with ASD were evaluated with Cognitive Assessment System (Naglieri \& Das, 1997) which is derived from the PASS theory (Planning, Attention, Simultaneous, Successive). CAS is a validated, norm-referenced test that assesses the students' cognitive abilities in two age bands (5:00 to 7:11 years old and 8:00 to 17:11 years old). In the present study were used tasks from the second age band (8:00 to 17:11 years). It is an individually administered test that takes between $45^{\prime}$ to $60^{\prime}$ minutes to complete. CAS involves tasks that grouped in four cognitive scales: 1) Planning scale (3 subtests), 2) Attention scale (3 subtests), 3) Simultaneous Coding scale (3 subtests) and 4) Successive scale (3 subtests). For the purpose of the current study the two cognitive scales 1) Planning scale and 2) Attention scale of the standard battery of CAS were used. Lower standard scores indicate learning difficulties. These two cognitive abilities are relevant with specific areas of academic performance (reading comprehension, spelling and mathematics (Kroesbergen, Van Luit, Naglieri, Taddei, \& Franchi, 2010).

\subsection{Design and Procedure}

The present study used three single-subject design cases with three adolescent boys diagnosed with Autism Spectrum Disorder. Measurements took place in the school setting during the school year 2020-2021 (October 2020-March 2021). Study adopted the pre and post intervention design. Specifically, all outcome measures were collected twice: 1) Phase 1 (before the intervention) and 2) Phase 2 (at the end of intervention), in which were measured the participants' anthropometric measurements (weight, height and waist circumference), motor performance and cognitive abilities. The students' parents provided written approval for all research procedures.

\subsection{Intervention}

The intervention program included moderate to vigorous aerobic exercise on a treadmill. The exercise intervention occurred three times per week and lasted for six months. Each session lasted 35 minutes and included treadmill jogging/running (20 min.), jumping on a trampoline (10 jumps) and gentle seated stretching (10 min.). After the aerobic program, a fruit and a cup of water were given to the 
participants. During each exercise session, participants were verbally reinforced (e.g., "keep going", "well done"). The exercise sessions took place at the begging of school curriculum. After the intervention program participants came back to their classroom activities.

\subsection{Statistical Analysis}

Descriptive statistics (mean and standard deviation) were calculated. A OneWay repeated measured Analysis of Variance (ANOVA) was conducted to evaluate the participants' pre- and post-training measurements in motor performance, on BMI and on cognitive abilities of students with ASD. Statistical analysis of the data was performed using Statistical Package for Social Sciences (SPSS) (version 25.0) (Norusis, 2012). A statistical significance $p$-value threshold was set at $<0.05$.

\subsection{Results}

Means and Standard Deviations for all anthropometric characteristics and other participants' descriptive characteristics (weight, BMI, waist circumference, motor skills and cognitive abilities) are presented in Table 1. According to the results the mean anthropometric characteristics for the three students with ASD reflect positive improvements at post-tests (after intervention aerobic program).

\subsubsection{Motor Performance}

Motor performance of students with ASD was assessed with Movement Assessment Battery for Children-2 (MABC-2). At Phase 1 (before the intervention) the motor performance of the two students with ASD was classified in "amber zone" and the other student's motor performance was classified in "red zone", according to the MABC-2 "Traffic Light" system, which denotes "at risk" of having a movement difficulty and significant movement difficulties, accordingly.

Table 1. Descriptive characteristics of the participants' pre and post-intervention aerobic program.

\begin{tabular}{ccc}
\hline Variables & \multicolumn{2}{c}{ Students with ASD (N = 3 Case Reports) } \\
\cline { 2 - 3 } Weight (Kg) & Pre & Post (6 months) \\
\hline Body Mass Index (BMI) & $79.3 \pm(7.09)$ & $75.63 \pm(7.69)$ \\
Waist Circumference & $29.02 \pm(1.25)$ & $27.64 \pm(1.25)$ \\
Manual Dexterity & $101 \pm(8.54)$ & $97.33 \pm(9.01)$ \\
Aiming \& Catching & $8.67 \pm(.58)$ & $16.00 \pm(2.65)$ \\
Balance (static \& dynamic) & $7.33 \pm(2.08)$ & $15.00 \pm(1.01)$ \\
Planning & $8.00 \pm(6.08)$ & $17.33 \pm(2.08)$ \\
Attention & $85 \pm(17.57)$ & $131 \pm(2.00)$ \\
\hline
\end{tabular}


Statistical criteria of One-Way repeated measured Analysis of Variance (ANOVA) was carried out in order to investigate whether there was any statistically significant effect of three participants' motor performance, when measured before and after participation in aerobic program. According to the results of the ANOVA repeated measured indicated a significant time effect on total score of MABC2 test (Wilks' Lambda $=0.016, \mathrm{~F}(2,1)=121.00, p<0.01, \mathrm{~h} 2=0.98$ ) and on subscales “Aiming and Catching” (Wilks' Lambda $=0.073, \mathrm{~F}(2,1)=25.47, p<$ $0.05, \mathrm{~h} 2=0.92$ ) and "Balance" (Wilks' Lambda $=0.047, \mathrm{~F}(2,1)=40.69, p<0.05$, $\mathrm{h} 2=0.95)$ of the MABC-2 test. There was not a significant time effect on Manual Dexterity subscale (Wilks' Lambda $=0.198, \mathrm{~F}(2,1)=8.08, p=0.105, \mathrm{~h} 2=0.80$ ) (Figure 1). According to the results, there was a statistical significant increase in scores over time on subscales "Aiming and Catching" and "Balance", suggesting that participation in the aerobic program can improve participants' motor proficiency.

\subsubsection{Cognitive Abilities}

Cognitive abilities (planning and attention) of students with ASD were assessed with Cognitive Assessment System (CAS). Statistical criteria of One-Way repeated measured Analysis of Variance (ANOVA) was carried out in order to investigate whether there was any statistically significant effect of three participants' executive functions, when measured before and after participation in aerobic program. According to the results of the ANOVA repeated measured indicated a significant time effect on Planning scale (Wilks' Lambda $=0.087, \mathrm{~F}(2,1)=21.09, p<0.05$, h2 $=0.91$ ). There was not a significant time effect on Attention scale (Wilks' Lambda $=0.303, \mathrm{~F}(2,1)=4.59, p=0.165, \mathrm{~h} 2=0.69)($ Figure 2$)$.

\subsection{Discussion}

The aim of the present study was to investigate the efficacy of an adapted aerobic program on gross and fine motor skills, body composition and cognitive abilities in three adolescent boys with Autism Spectrum Disorders (ASD). Results showed that the applied 6-months aerobic training program was effective to enhance

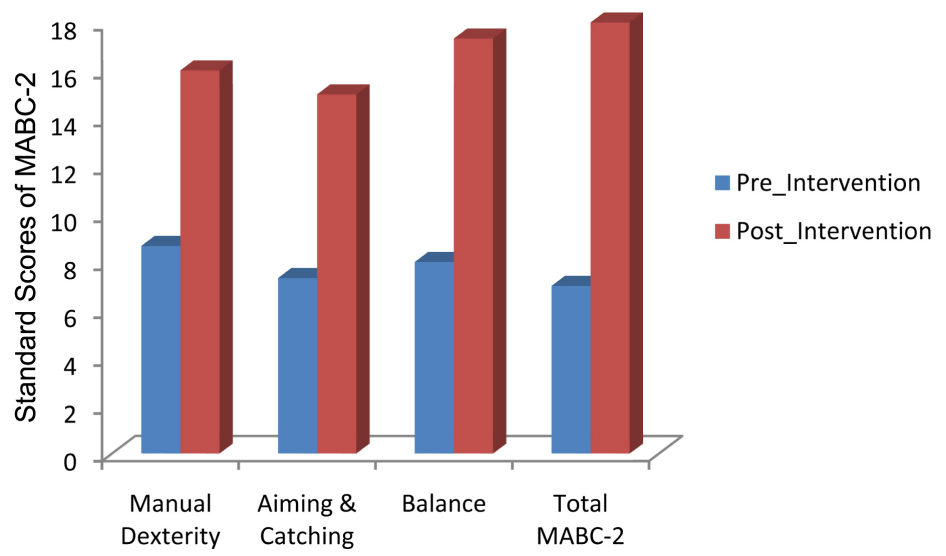

Figure 1. Effect of aerobic program in three students' with ASD motor performance. 


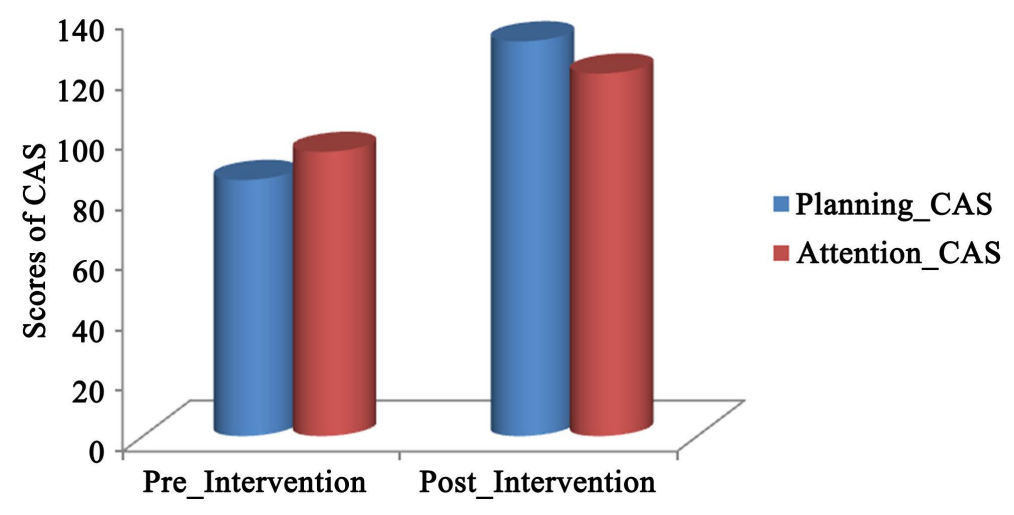

Figure 2. Effect of aerobic program in three students' with ASD cognitive abilities.

visual-motor coordination skills, object control skills, balance skills and the cognitive ability of planning in students with ASD. Also, it was found that the aerobic program had significant effect on weight outcomes (BMI and waist Circumference) of adolescents with ASD. This is coherent with previous studies suggesting that exercise interventions could have a beneficial effect not only on the motor proficiency and cognitive abilities but also on physical health and fitness in students with ASD (Battaglia, Agrò, Cataldo, Palma, \& Alesi, 2019).

Our first hypothesis was that adapted aerobic training program would improve motor performance and body composition of students with ASD and this hypothesis was partially confirmed. More specifically, students with ASD improved in two of three subscales of MABC-2 test: "Aiming \& Catching" such as catching and throwing a ball with one hand, throwing a ball at wall target and "Balance" such as two-board balance, walking toe-to-heel backwards, zig-zag hopping. In the current study the three students with ASD were classified as overweight according to the BMI cut-off points. According to weight outcomes it was found a significant reduction on waist circumference as well as on BMI of participants. The present results are in agreement with previous research as reported significant improvements in a range of fine and gross motor skills, locomotor activities, balance skills and body combination (Sowa \& Meulenbroek, 2012; Lang, KernKoegel, Ashbaugh, Regester, Ence, \& Smith, 2010). Shahrasfenghar, Arabameri, Daneshfar, Ghasemi and Kashi (2019) investigated the efficacy of aerobic exercise on motor skills and body composition in children with ASD. The intervention lasted for 12 sessions of 90 minutes each one. According to the results, aerobic exercise program improved significantly the participants' motor proficiency and body composition. Researchers concluded that aerobic exercise can be used as a useful non-pharmacological intervention in order to improve the motor skills and the weight outcomes of children with ASD. Another study showed that a 9-months walking intervention program increased physical strength and reduced BMI in ten adolescents with ASD (Pitetti, Rendoff, Grover, \& Beets, 2007). Brand, Jossen, Holsboer-Trachsler, Pühs and Gerber (2015) investigated the impact of aerobic exercise training on motor performance in ten children with ASD (mean age: 10 years). The aerobic intervention program lasted for three consecutive weeks 
and the training frequency included 60-minute sessions for three sessions per week. Each training session consisted of a 30-minute bicycle workout and 30minutes of training in balance skills. It was found significant improvement on participants' motor skills, especially on ball playing such as catching a ball and throwing a ball with one or with two hands and balancing such as standing on one leg, forward, jumping zigzag, balancing on a beam.

According to Case and Yun (2019), exercise interventions have a large effect on gross motor skills among children with ASD. Specifically, the frequency of interventions plays an important role. Exercise interventions that were less than total 16 hours hadn't had the expected improvement among the participants with ASD. Colombo-Dougovito and Block (2019) reported that exercise interventions not only can help improve motor proficiency but also can increase the participation in physical activities for children and adolescents with ASD. Ceccarelli, Ferrante, Gazzola, Marzocchi, Nobile, Molteni and Crippa (2020) highlighted that motor skills training programs are of major importance and should be integrated in rehabilitation programs for children with ASD because of the well-documented existence of motor impairments in children with ASD. The positive effects of adapted exercise programs on children with ASD will be effective in increasing their overall quality of life (Akın \& Alp, 2019).

Our second hypothesis was that the 6-months intervention aerobic program would have significant effect on cognitive abilities of students with ASD and this hypothesis was partially confirmed as participants improved in one of two assessed cognitive scales. More specifically, according to the results it was found a significant time effect on Planning scale of CAS cognitive test. Planning is a fundamental cognitive process that can be defined as ability to "think about the future". It is about a strategy in which be involved a sequence of thoughts and actions in order to be achieved a specified goal (Hill, 2004). Planning as a complex cognitive ability enables people to adopt their behavior. People with ASD encounter planning deficits in everyday activities that encounter difficulties on social engagement and coping with unexpected facts (Olde Dubbelink, \& Geurts, 2017; Brunsdon, Colvert, Ames, Garnett, Gillan, Hallet, \& Happé, 2015). Cognitive deficits leads to lower academic performance in children with ASD as they are connected with attention difficulties, intellectual disabilities, repetitive and restricted behaviors, poor orientation skills as well as poor eye-contact. These skills have a negative effect on social integration and participation in physical activities (Srinivasan, Pescatello, \& Bhat, 2014). Oriel, George, Peckus and Semon (2011) evaluated the efficacy of an aerobic exercise program in youth children ( 3 - 6 years old) with ASD on academic engagement. Students performed $15 \mathrm{~min}$ jogging or jumping on a trampoline for 10 weeks and afterwards were attended in their classroom activities. It was found that participants exhibit decreased stereotypic behaviors and improved academic responding. Ringenbach, Lichtsinn and Holzapfel (2015) investigated the efficacy of Assisted Cycling Therapy (ACT) on cognitive and motor functioning in ten adolescents with ASD. Exercise intervention with bicycle improved significantly participants' inhibition and plan- 
ning cognitive abilities as well as exercise perception.

\subsection{Conclusion}

Participation in physical exercise has shown many benefits on symptomatology and on the reduction of comorbidities in students with Autism Spectrum Disorder. It is not only the child's physical well-being that is important, but also the psychological and social well-being, as well as reduction of autism-specific difficulties in children and adolescents with ASD (Srinivasan, Pescatello, \& Bhat, 2014). According to Bremer, Crozier and Lloyd's study (Bremer, Crozier, \& Lloyd, 2016) exercise can reduce stereotypic behaviors and improve social-emotional functioning in children and youth with ASD. The health outcomes of exercise are beyond dispute. Physical activity is undoubtedly important for the emotional and physical health as well as cognitive abilities (Bidzan-Bluma \& Lipowska, 2018). Research results highlight the intercorrelated link between motor performance and cognitive development during childhood (Rakison \& Woodward, 2008; Sommerville \& Decety, 2006). Students with ASD exhibited improved cognitive, social and behavioral skills after performing aerobic exercises (Neely, Rispoli, Gerow, \& Ninci, 2015). Physical activity can also improve cognitive development in overweight children (Best, 2010; Davis, Tomporowski, McDowell, Austin, Miller, Yanasak, Allison, \& Naglieri, 2011).

\subsection{Recommendations}

The regular and active participation in physical activities has a positive impact on everyday life activities and independence of people with Autism Spectrum disorder. Developing exercise intervention programs to improve motor proficiency, physical fitness and cognitive abilities of children and youth with ASD should be a priority by the community. Improvements on fundamental motor skills may lead to increased participation in physical activities among people with ASD. This contributes to increased social and communicative skills, improved physical fitness and better health outcomes (Henderson, Noren, Williams, Fuller, \& Mortensen-Stout, 2016). Exercise programs should be planned on participants' with ASD individual needs on a daily and structured basis. Interventions should be encounter the high levels of obesity among children and adults with ASD in order to involve the appropriate dietary changes as the ultimate aim is to improve their overall health-related physical fitness (Pan, Tsai, Chu, Sung, Ma, \& Huang, 2016).

\section{Acknowledgements}

We would like to thank the parents and students with Autism Spectrum Disorder that contributed to conduct this study.

\section{Conflicts of Interest}

The authors declare no conflicts of interest regarding the publication of this paper. 


\section{References}

Akın, S., \& Alp, H. (2019). Effect of Adapted Game-Aided Physical Education Program on the Motor Skills of Children with Autism Spectrum Disorders: Longitudinal Case Study. Journal of Curriculum and Teaching, 8, 63-72. https://doi.org/10.5430/jct.v8n3p63

Alesi, M., Battaglia, G., Roccella, M., Testa, D., Palma, A., \& Pepi, A. (2014). Improvement of Gross Motor and Cognitive Abilities by an Exercise Training Program: Three Case Reports. Neuropsychiatric Disease and Treatment, 10, 479-485. https://doi.org/10.2147/NDT.S58455

American Psychiatric Association (APA) (2013). Diagnostic and Statistical Manual of Mental Disorders (5th ed.). (DSM-V), American Psychiatric Association. https://doi.org/10.1176/appi.books.9780890425596

Arzoglou, D., Tsimaras, V., Kotsikas, G., Fotiadou, E., Sidiropoulou, M., Proios M., \& Bassa, E. (2013). The Effect of Traditional Dance Training Program on Neuromuscular Coordination of Individuals with Autism. Journal of Physical Education and Sport, 13, 563 569.

Battaglia, G., Agrò, G., Cataldo, P., Palma, A., \& Alesi, M. (2019). Influence of a Specific Aquatic Program on Social and Gross Motor Skills in Adolescents with Autism Spectrum Disorders: Three Case Reports. Journal of Functional Morphology and Kinesiology, 4, 110. https://doi.org/10.3390/jfmk4020027

Best, J. R. (2010) Effects of Physical Activity on Children's Executive Function: Contributions of Experimental Research on Aerobic Exercise. Developmental Review, 30, 331-351. https://doi.org/10.1016/j.dr.2010.08.001

Bidzan-Bluma, I., \& Lipowska, M. (2018). Physical Activity and Cognitive Functioning of Children: A Systematic Review. International Journal of Environmental Research and Public Health, 15, 1-13. https://doi.org/10.3390/ijerph15040800

Brand, S., Jossen, S., Holsboer-Trachsler, E., Pühse, U., \& Gerber, M. (2015). Impact of Aerobic Exercise on Sleep and Motor Skills in Children with Autism Spectrum DisordersA Pilot Study. Neuropsychiatric Disease \& Treatment, 11, 1911-1920. https://doi.org/10.2147/NDT.S85650

Bremer, E., Crozier M., \& Lloyd, M. (2016). A Systematic Review of the Behavioural Outcomes Following Exercise Interventions for Children and Youth with Autism Spectrum Disorder. Autism, 20, 899-915. https://doi.org/10.1177/1362361315616002

Broder-Fingert, S., Brazauskas, K., Lindgren, K., Iannuzzi, D., \& Van Cleave, J. (2014). Prevalence of Overweight and Obesity in a Large Clinical Sample of Children with Autism. Academic Pediatrics, 14, 408-414. https://doi.org/10.1016/j.acap.2014.04.004

Brunsdon, V. E. A., Colvert, E., Ames, C., Garnett, T., Gillan, N., Hallet, V., \& Happé, F. (2015). Exploring the Cognitive Features in Children with Autism Spectrum Disorder, Their Co-Twins, and Typically Developing Children within a Population-Based Sample. Journal of Child Psychology and Psychiatry, 56, 893-902.

https://doi.org/10.1111/jcpp.12362

Case, L., \& Yun, J. (2019). The Effect of Different Intervention Approaches on Gross Motor Outcomes of Children with Autism Spectrum Disorder: A Meta-Analysis. Adapted Physical Activity Quarterly, 36, 501-526. https://doi.org/10.1123/apaq.2018-0174

Ceccarelli, S. B., Ferrante, C., Gazzola, E., Marzocchi, G.-M., Nobile, M., Molteni, M., \& Crippa, A. (2020). Fundamental Motor Skills Intervention for Children with Autism Spectrum Disorder: A 10-Year Narrative Review. Children, 7, 250.

https://doi.org/10.3390/children7110250

Cole, T. J., Bellizzi, M. C., Flegal, K. M., \& Dietz, W. H. (2000). Establishing a Standard 
Definition for Child Overweight and Obesity Worldwide: International Survey. BMJ, 320, 1240. https://doi.org/10.1136/bmj.320.7244.1240

Colombo-Dougovito, A. M., \& Block, M. E. (2019). Fundamental Motor Skill Interventions for Children and Adolescents on the Autism Spectrum: A Literature Review. Review Journal of Autism and Developmental Disorders, 6, 159-171.

https://doi.org/10.1007/s40489-019-00161-2

Dartt, K. (2015). Effects of Physical Activity and Aquatics Programs on Problem Behaviors in Children with Diagnosed Disabilities and Behavior Disorders (p. 104). Senior Honors Theses, the College at Brockport.

https://digitalcommons.brockport.edu/honors/104

Davis, C. L., Tomporowski, P. D., McDowell, J. E., Austin, B. P., Miller, P. H., Yanasak, N. E., Allison, J. D., \& Naglieri, J. A. (2011). Exercise Improves Executive Function and Achievement and Alters Brain Activation in Overweight Children: A Randomized, Controlled Trial. Health Psychology, 30, 91-98. https://doi.org/10.1037/a0021766

Deorari, M., \& Bhardwaj, I. (2014). Effect of Yogic Intervention on Autism Spectrum Disorder. Yoga Mimamsa, 46, 81-84. https://doi.org/10.4103/0044-0507.159744

Ferreira, J. P., Toscano, C. V. A., Rodrigues, A. M., Furtado, G. E., Barros, M. G., Wanderley, R. S., \& Moreira Carvalho, H. M. (2018). Effects of a Physical Exercise Program (PEPAut) on Autistic Children's Stereotyped Behavior, Metabolic and Physical Activity Profiles, Physical Fitness, and Health-related Quality of Life: A Study Protocol. Frontiers in Public Health, 6, Article No. 47. https://doi.org/10.3389/fpubh.2018.00047

Fragala-Pinkham, M. A., \& Haley, S. M. (2011). Group Swimming and Aquatic Exercise Programme for Children with Autism Spectrum Disorders: A Pilot Study. Developmental Neurorehabilitation, 14, 230-241. https://doi.org/10.3109/17518423.2011.575438

Gowen, E., \& Hamilton A. (2013). Motor Abilities in Autism: A Review Using a Computational Context. Journal of Autism in Developmental Disorder, 43, 323-344.

https://doi.org/10.1007/s10803-012-1574-0

Greek Ministry of Education and Religious Affairs, Institute of Educational Policy (2003). National Educational Curriculum for Students with Autism Spectrum Disorders. Greek Ministry of Education and Religious Affairs, Institute of Educational Policy.

Healy, S., Nacario, A., Braithwaite, R. E., \& Hopper, C. (2018). The Effect of Physical Activity Interventions on Youth with Autism Spectrum Disorder: A Meta-Analysis. Autism Research, 11, 818-833. https://doi.org/10.1002/aur.1955

Henderson, H., Noren, S., Williams, D., Fuller, A., \& Mortensen-Stout, V. (2016). The Effects of a Physical Education Program on the Motor Skill Performance of Children with Autism Spectrum Disorder. Palaestra, 30, 41-50.

Henderson, S. E., Sugden, D. A., \& Barnett, A. L. (2007). Movement Assessment Battery for Children-2(2nd ed.). The Psychological Corporation. https://doi.org/10.1037/t55281-000

Henderson, S. E., Sugden, D. A., Barnett, A. L., Brown, T., \& Lalor, A. (2009). Movement Assessment Battery for Children-Second Edition. Physical \& Occupational Therapy in Pediatrics, 29, 86-103. https://doi.org/10.1080/01942630802574908

Hill, E. L. (2004). Executive Dysfunction in Autism. Trends in Cognitive Sciences, 8, 26-32. https://doi.org/10.1016/j.tics.2003.11.003

Hinckson, E. A., Dickinson, A., Water, T., \& Sands, M. (2013). Physical Activity, Dietary Habits and Overall Health in Overweight and Obese Children and Youth with Intellectual Disability or Autism. Research in Developmental Disabilities, 34, 1170-1178.

https://doi.org/10.1016/j.ridd.2012.12.006 
Kiphard, E. J., \& Schilling, F. (2007). Körperkoordinationstestfür Kinder. Beltz Test GmbH.

Kroesbergen, E., Van Luit, J., Naglieri, J., Taddei, S., \& Franchi, E. (2010), PASS Processes and Early Mathematics Skills in Dutch and Italian Kindergarteners. Journal of Psychoeducational Assessment, 28, 585-593. https://doi.org/10.1177/0734282909356054

Lang, R., Kern-Koegel, L., Ashbaugh, K., Regester, A., Ence, W., \& Smith, W. (2010). Physical Exercise and Individuals with Autism Spectrum Disorders: A Systematic Review. Research in Autism Spectrum Disorders, 4, 565-576.

https://doi.org/10.1016/j.rasd.2010.01.006

McMullen, S. (2014). Childhood Obesity: The Impact on Long-Term Risk of Metabolic and CVD Is Not Necessarily Inevitable. Proceedings of the Nutrition Society, 73, 389-396. https://doi.org/10.1017/S0029665114000111

Naglieri J. A., \& Das, J. P. (1997), Cognitive Assessment System. Reverside Publising.

Neely, L., Rispoli, M., Gerow, S., \& Ninci, J. (2015). Effects of Antecedent Exercise on Academic Engagement and Stereotypy during Instruction. Behavior Modification, 39, 98116. https://doi.org/10.1177/0145445514552891

Norusis, M. (2012). IBM SPSS Statistics 21 Guide to Data Analysis. SPSS Inc.

Olde Dubbelink, L. M. E., \& Geurts, H. M. (2017). Planning Skills in Autism Spectrum Disorder across the Lifespan: A Meta-Analysis and Meta-Regression. Journal Autism Developmental Disorder, 47, 1148-1165. https://doi.org/10.1007/s10803-016-3013-0

Oriel, K. N., George, C. L., Peckus, R., \& Semon, A. (2011). The Effects of Aerobic Exercise on Academic Engagement in Young Children with Autism Spectrum Disorder. Pediatric Physical Therapy, 23, 187-193. https://doi.org/10.1097/PEP.0b013e318218f149

Pan, C.-Y. (2011). The Efficacy of an Aquatic Program on Physical Fitness and Aquatic Skills in Children with and without Autism Spectrum Disorders. 7-12 Years Old. Research in Autism Spectrum Disorders, 5, 657-665. https://doi.org/10.1016/j.rasd.2010.08.001

Pan, C.-Y., Tsai, C.-L., Chu, C.-H., Sung, M.-C., Ma, W.-Y., \& Huang, C.-Y. (2016). Objectively Measured Physical Activity and Health-Related Physical Fitness in Secondary School-Aged Male Students with Autism Spectrum Disorders. Physical Therapy, 96, 511520. https://doi.org/10.2522/ptj.20140353

Pitetti, K. H., Rendoff, A. D., Grover, T., \& Beets, M. W. (2007). The Efficacy of a 9Month Treadmill Walking Program on the Exercise Capacity and Weight Reduction for Adolescents with Severe Autism. Journal of Autism and Developmental Disorders, 37, 997-1006. https://doi.org/10.1007/s10803-006-0238-3

Rakison, D. H., \& Woodward, A. L. (2008). New Perspectives on the Effects of Action on Perceptual and Cognitive Development. Developmental Psychology, 44, 1209-1213. https://doi.org/10.1037/a0012999

Ringenbach, S. D. R., Lichtsinn, K. C., \& Holzapfel, S. D. (2015). Assisted Cycling Therapy (ACT) Improves Inhibition in Adolescents with Autism Spectrum Disorder. Journal of Intellectual \& Developmental Disability, 40, 376-387. https://doi.org/10.3109/13668250.2015.1080352

Rosenblatt, L. E., Gorantla, S., Torres, J. A., Yarmush, R. S., Rao, S., Park, E. R., Denninger, J. W., Benson, H., Fricchione, G. L., Bernstein, B., \& Levine, J. B. (2011). Relaxation Response-Based Yoga Improves Functioning in Young Children with Autism: A Pilot Study. Journal of Alternative Complementary Medicine, 17, 1029-1035. https://doi.org/10.1089/acm.2010.0834

Sequeira, S., \& Ahmed, M. (2012). Meditation as a Potential Therapy for Autism: A Review. Autism Research and Treatment, 2012, Article ID: 835847.

https://doi.org/10.1155/2012/835847 
Shahrasfenghar, A., Arabameri, E., Daneshfar, A., Ghasemi, A., \& Kashi, A. (2019). The Effect of Aerobic Exercise on Motor Skills and Body Composition of Children with Autism. Journal of Health and Care, 20, 332-341. https://doi.org/10.29252/jhc.20.4.332

Sommerville, J. A., \& Decety, J. (2006). Weaving the Fabric of Social Interaction: Articulating Developmental Psychology and Cognitive Neuroscience in the Domain of Motor Cognition. Psychonomic Bulletin \& Review, 13, 179-200.

https://doi.org/10.3758/BF03193831

Sowa, M., \& Meulenbroek, R. (2012). Effects of Physical Exercise on Autism Spectrum Disorders: A Meta-Analysis. Research in Autism Spectrum Disorders, 6, 46-57. https://doi.org/10.1016/j.rasd.2011.09.001

Srinivasan, S. M., Pescatello, L. S., \& Bhat, A. N. (2014). Current Perspectives on Physical Activity and Exercise Recommendations for Children and Adolescents with Autism Spectrum Disorders. Physical Therapy, 94, 875-889.

https://doi.org/10.2522/ptj.20130157

Tyler, C. V., Schramm, S. C., Karafa, M., Tang, A. S., \& Jain, A. K. (2011). Chronic Disease Risks in Young Adults with Autism Spectrum Disorder: Forewarned Is Forearmed. American Association on Intellectual and Developmental Disabilities, 116, 371-380. https://doi.org/10.1352/1944-7558-116.5.371

Xavier, J., Gauthier, S., Cohen, D., Zahoui, M., Chetouani, M., Villa, F., Berthoz, A., \& Anzalone, S. (2018). Interpersonal Synchronization, Motor Coordination, and Control Are Impaired during a Dynamic Imitation Task in Children with Autism Spectrum Disorder. Frontiers in Psychology, 9, Article ID: 1467.

https://doi.org/10.3389/fpsyg.2018.01467

Yanardag, M., Erkan, M., Yılmaz, İ., Arıcan, E., \& Düzkantar, A. (2015). Teaching Advance Movement Exploration Skills in Water to Children with Autism Spectrum Disorders. Research in Autism Spectrum Disorders, 9, 121-129. https://doi.org/10.1016/j.rasd.2014.10.016

Yilmaz, I., Yanardag, M., Birkan, B., \& Bumin, G. (2004). Effects of Swimming Training on Physical Fitness and Water Orientation in autism. Paediatrics International, 46, 624626. https://doi.org/10.1111/j.1442-200x.2004.01938.x

Young, S., \& Furgal, K. (2016). Exercise Effects in Individuals with Autism Spectrum Disorder: A Short Review. Autism-Open Access, 6, Article ID: 1000180.

https://doi.org/10.4172/2165-7890.1000180 